E3S Web of Conferences 1, 32003 (2013)

DOI: $10.1051 / \mathrm{e} 3 \operatorname{sconf} / 20130132003$

(C) Owned by the authors, published by EDP Sciences, 2013

\title{
Environmental Geochemistry of Potentially Toxic elements in thermal springs in the Sabalan Volcanic Field, NW Iran
}

\author{
S. Modabberi ${ }^{1}$ \\ ${ }^{1}$ School of Geology, University College of Science, University of Tehran, IRAN, modabberi@ut.ac.ir, \\ s_modabberi@yahoo.com
}

\begin{abstract}
Thermal springs are widely used by tourists for treatment of dermal diseases and other therapeutic applications. In Iran, thermal springs occur in Northwestern part mainly surrounding the Mount Sabalan which attract hundreds of thousands of tourists annually. Two clusters of springs in Neer and Meshkinshahr areas including 16 thermomineralic springs have been studied in this research and they were sampled twice in May and November in order to investigate the seasonal changes of trace elements in dry and wet seasons. The samples were analyzed in Acme Lab, Canada for 72 elements. Trace element concentrations indicate that most of the elements show concentration well beyond the guideline values for drinking water. While the two sets of samples were taken within a 6 months interval, the elements show slight or no variation from first period to the second and in some cases. Arsenic shows a variation of 5-5834 $\mu \mathrm{g} / 1$ and the mean As value is 160 times the guideline values $(10 \mu \mathrm{g} / \mathrm{l})$. Other toxic elements with high concentration are $\mathrm{B}, \mathrm{Fe}, \mathrm{Mn}$, $\mathrm{Sb}$, and $\mathrm{Si} . \mathrm{Mn}$ and $\mathrm{Sb}$ shows exeedance of 12 and 11.5 times respectively. Correlation coefficient and principal component analysis of analytical data indicate that $\mathrm{Cl}, \mathrm{As}, \mathrm{B}, \mathrm{Ba}, \mathrm{Br}$, and $\mathrm{V}$ show very strong mutual correlation coefficients implying their relationship and common source and fate in the hydrothermal fluid carrying them. These elements fall in the component 1 of PCA. This group of elements is supposed to be derived and sourced from the magmatic-hydrothermal system and through the interaction of hydrothermal fluids with rocks they passed through. Because of discharge of the thermal springs into the nearby streams intended to be used for drinking water and also vast application of spring waters in balneological uses, they may have adverse environmental and health impacts on tourists that expose themselves to this contaminants through balneological applications.
\end{abstract}

Keywords: Environmental Geochemistry, Sabalan, Thermal Springs, Trace elements, Arsenic contamination, Iran

\section{Introduction}

Thermal springs are frequently found in active or recently active volcanic areas around the world. In most places they are used for balneological and bathing purposes, e.g. in Turkey, Italy, Iceland, New Zealand, Portugal and so on. They have been well-studied in Turkey which have numerous spring by Davraz (2008), Elhatip et al., (2004), Gemici et al., (2004), Gemici and Filiz (2001), Gemici and Tarcan (2004), Gultekin et al., (2011), Yalcin (2007) and many others. In fact the Turkish baths owe their fame to the geological features producing them. In the neighborhood, Iranian thermal springs exhibit similarities and also differences however they are least studied and few information are available especially on their geochemistry of trace elements.

In addition to the role of trace elements in deciphering the source and processes occurring in the hydrothermal reservoir, they are frequently used in monitoring environmental and geomedical impacts (Guo and Wang 2009, Bargagli et al. 1997, Elhatip et al. 2004, Loppi 2001, Cruz and Franza 2006, Federico et al. 2004, Valentino and Stanzione 2004, Vengosh et al. 2002).

Thermal springs are usually enriched in some potentially toxic elements inherited from the same hydrothermal reservoir. According to Smedley and Kinniburgh (2002), and Yoshizuka et al. (2010), arsenic is a ubiquitous and persistent element found in volcanic gases and emanations. It is estimated that about $1.9 \mathrm{Gg}$ arsenic are annually released to the atmosphere by volcanoes (Nriagu 1989).

As is regarded as the first hazardous contaminant 
found frequently in groundwater and drinking water resources all around the world and the list of arsenic affected areas is monthly updated and new areas are added to it. Gemici and his colleagues found also high concentrations of potentially toxic elements in Turkish hot spring including $\mathrm{As}, \mathrm{B}, \mathrm{Hg}, \mathrm{Pb}, \mathrm{Zn}, \mathrm{Mn}, \mathrm{Li}$. Pehlivan (2003) reported Kirkgecit and Ozancik hot springs in Turkey rich in $\mathrm{Hg}, \mathrm{Ni}, \mathrm{Cr}, \mathrm{Cu}$ and $\mathrm{Fe}$. Natural contribution of harmful elements (As, Be, Mn, Sb, Se, $\mathrm{Hg}, \mathrm{W}, \mathrm{U}, \mathrm{Mo}, \mathrm{V}, \mathrm{Cr}$, ) has been mentioned by Lima et al. (2003) in thermal groundwaters of Ischia Island, southern Italy.

Thermal springs in Iran are mostly concentrated around Quaternary volcanic centers or along major faults. A large number of thermal springs are located in NW Iran in Ardabil Province due to the geological situation mainly related to last activities of Sabalan Volcano. Annually hundreds of thousands of tourists use them for bathing and balneological purposes. However, the thermal springs of this area have not been studied in detail especially their trace element geochemistry. This paper attempts to investigate the concentration of trace elements in spring waters, to characterize the source processes and geochemistry of waters, to genetic deduction and to study their possible impacts on tourists exposing themselves to potentially toxic elements.

\section{Methods and Materials}

The study area is located between the latitudes $37^{\circ} 55^{\prime}$ and $38^{\circ} 20^{\prime} \mathrm{E}$ and longitudes $47^{\circ} 35^{\prime}$ and $48^{\circ} 05^{\prime} \mathrm{N}$ at a distance of about $600 \mathrm{~km}$ from Tehran, the capital city of Iran. In this study, 16 thermal springs have been studied in two areas of Neer and Meshkinshahr.

The spring waters were sampled twice in wet (May) and dry (November) seasons. Water samples were collected in $250 \mathrm{ml}$ polyethylene bottles which had been acid washed previously and rinsed with spring water three times before sampling. $2.5 \mathrm{ml}$ ultrapure Merck $\mathrm{HNO}_{3}$ was added to the sample to $\mathrm{pH} 2$ immediately after sampling, in order to prevent the formation of heavy metal complexes. Acidified samples were analyzed for major and trace elements (72 elements) with an ICP-MS at ACME Labs, Canada.

\section{Results}

Water temperature at the surface ranges from 33.2 to $80.1^{\circ} \mathrm{C}$, mainly between $34-45^{\circ} \mathrm{C}$. The spring waters are slightly acidic to circum-neutral in Meshkinshahr springs with $\mathrm{pH}$ values ranging from 5.2 to 6.7 and the springs in Neer area are showing values between 6.4-7.4.

Trace element analysis results for thermal springs in two periods of sampling are presented in Table 1 . Comparison of trace elements in two series of analysis indicate that water samples of the first series (sampled in May) are generally more enriched in trace elements, i.e. the higher the discharge of the spring, the higher the concentration of trace elements.
According to the Table 1, thermal springs of Neer area are more enriched in most of trace elements

Tab.1 The summarized results of trace element analysis in thermal springs of Neer $(n=6)$ and Meshkinshahr $(\mathrm{n}=10)$. Concentration of elements in $\mu \mathrm{g} / \mathrm{l}$ except for $\mathrm{Cl}$ which is in $\mathrm{mg} / \mathrm{l}$. Guideline values are presented in parentheses

\begin{tabular}{|c|c|c|c|c|c|c|}
\hline \multirow[b]{2}{*}{ Parameter } & \multicolumn{3}{|c|}{ Neer springs } & \multicolumn{3}{|c|}{ Meshkinshahr springs } \\
\hline & Min & Max & Ave. & Min & Max & Average \\
\hline Elevation & 1648 & 1709 & 1682 & 2011 & 2289 & 2102 \\
\hline $\mathbf{Q}(\mathbf{l} / \mathbf{s})$ & 0.5 & 1.8 & 1.2 & 0.8 & 14 & 3.52 \\
\hline $\mathbf{T}\left({ }^{\circ} \mathbf{C}\right)$ & 34.4 & 67.1 & 44.2 & 33.2 & 80.1 & 45.4 \\
\hline $\mathrm{EC}(\boldsymbol{\mu S} / \mathbf{c m})$ & 1010 & 11400 & 9173 & 1005 & 6010 & 1942 \\
\hline pH & 6.4 & 7.4 & 6.9 & 5.2 & 6.7 & 6.1 \\
\hline Al (200) & 5 & 580 & 126 & 6 & 894 & 172 \\
\hline As (10) & 10 & 5834 & 3470 & 21.3 & 2493 & 452 \\
\hline B (2400) & 952 & 24894 & 18883 & 69 & 11299 & 2847.9 \\
\hline $\mathrm{Cl}(\mathrm{mg} / \mathrm{l})(0.5)$ & 120 & 2886 & 2062 & 7 & 1525 & 327 \\
\hline $\mathrm{Cu}(2000)$ & 1.2 & 5 & 2.95 & 0.9 & 4.1 & 1.76 \\
\hline $\mathrm{Fe}(300)$ & 26 & 3343 & 966 & 5 & 13478 & 3052 \\
\hline Mn (50) & 0.53 & 264.5 & 102 & 2.43 & 612.68 & 273 \\
\hline Pb (10) & 0.5 & 6.7 & 1.5 & 0.1 & 2 & 0.54 \\
\hline Sb (20) & 0.52 & 206.9 & 93 & 0.48 & 254 & 40 \\
\hline $\mathbf{S i}$ & 28154 & 43827 & 34294 & 12667 & 86305 & 52126 \\
\hline Zn (5000) & 0.9 & 21.3 & 7.2 & 1.3 & 53.6 & 17.8 \\
\hline
\end{tabular}

including $\mathrm{As}, \mathrm{B}, \mathrm{Ba}, \mathrm{Br}, \mathrm{Cl}, \mathrm{Cu}, \mathrm{Li}, \mathrm{Rb}, \mathrm{S}, \mathrm{Sr}$, and $\mathrm{V}$ in comparison with the springs of Meshkinshahr area, instead, springs in the latter are more enriched in $\mathrm{Al}, \mathrm{Fe}$, $\mathrm{Mn}, \mathrm{Si}$, and Znhowever slightly enriched in Neer springs. Most of these elements show concentrations much higher than guideline values.

The lowest concentration of arsenic was measured in dry season in N3 spring however all other samples in the Neer area show the highest amount of As up to $5835 \mu \mathrm{g} / \mathrm{l}$ with average values of 4538 and $3781 \mu \mathrm{g} / \mathrm{l}$ in wet and dry seasons respectively. Meshkinshahr springs indicate lower As concentrations while M1 has a concentration of about $2500 \mu \mathrm{g} / \mathrm{l}$. It is significant to note that all of the samples fall above the guideline values $(10 \mu \mathrm{g} / \mathrm{l})$ defined by regulatory organizations (WHO, EPA and EU) (Tables 2 and 4).

Boron is ubiquitous in thermal springs of Tethyian region including Turkish springs. Boron concentration is higher in Neer springs than Meshkinshahr springs with a maximum content of $24894 \mu \mathrm{g} / 1$.

\section{Discussion}

The analytical data for two periods of sampling indicate no significant difference for trace elements concentrations in these two periods.

The meteoric recharge of the hydrothermal reservoir is supposed to be responsible for the supply of $\mathrm{Mg}, \mathrm{Ca}$ 
and $\mathrm{SO}_{4}$, since based on the analytical and statistical data, these elements may have a different source than other elements especially of $\mathrm{K}, \mathrm{Cl}, \mathrm{As}, \mathrm{B}, \mathrm{Ba}, \mathrm{Br}, \mathrm{Li}, \mathrm{Sr}, \mathrm{Rb}$ and $\mathrm{V}$. The latter group of elements are ascribed to the magmatic source of the hydrothermal fluid and also to interaction of the fluid with country rocks passing through it while rising toward the surface and before mixing with meteoric-ground water.

Most of the thermal waters in the Neer area contain more than $18000 \mu \mathrm{g} / \mathrm{l}$ of boron. High boron content is attributed to deep water circulation of hydrothermal fluid through the volcanic rocks.

Si concentration varies between 14237 to 86306 $\mu \mathrm{g} / \mathrm{l}$ and its obvious source is alteration of silicate minerals especially of $\mathrm{K}$-feldspar.

$\mathrm{Al}$ and $\mathrm{Fe}$ values are interestingly low compared to other elements. Their maximum concentrations are 894 and $13478 \mu \mathrm{g} / \mathrm{l}$ respectively however in most of the samples they show very low contents.

As is highly enriched in all samples and it is in accordance with the idea that young volcanism in NW Iran in accompanied by arsenic enrichment, mentioned previously by Modabberi and Moore (2004). Valentino and Stanzione (2003) referred the As enrichment to water-rock interactions and also to rising of hot fluids and suggested that progressive increase of As in waters with increasing time of residence is generally matched by $\mathrm{Hg}$ depletion because of the introduction of mercury into newly formed alteration minerals. This is the case that is observed in the study area where $\mathrm{Hg}$ is most of the samples has a concentration below the detection limit of the analysis $(0.1 \mu \mathrm{g} / 1)$.

$\mathrm{Pb}, \mathrm{Zn}$ and $\mathrm{Cu}$ concentrations also are very low in thermal water samples and by no means reach the guideline values for environmental protection and drinking water.

$\mathrm{EC}, \mathrm{Cl}, \mathrm{As}, \mathrm{B}, \mathrm{Cu}$, and $\mathrm{V}$ show very strong mutual correlation coefficients higher than 0.8 indicating their relationship in the hydrothermal fluid carrying them out of the geothermal system.

$\mathrm{pH}$ has a negative strong correlation with $\mathrm{Zn}$, however shows a medium coefficient with other parameters. Al only shows a strong correlation with $\mathrm{Fe}$. $\mathrm{Si}$ has a medium but negative correlation with $\mathrm{Al}$ and Fe. Principal component analysis calculation indicates that the same show a close relationship. In the first component, parameters of EC, As, B, Na, and $\mathrm{V}$ show values higher than 0.75 and probably have the same source and fate of transport for which the most plausible source is suggested to be magmatic -hydrothermal source. In second component, $\mathrm{Al}$ and $\mathrm{Fe}$ have been located and the third one only consists of $\mathrm{Mn}$.

The hot springs flows into Khiav Chay and other streams on which two dams are under construction and they are supposed to supply the water for drinking and agricultural -industrial needs. Hence, the impact of thermal springs with the high concentrations of potentially toxic elements on the deterioration of water quality in main rivers is of vital importance and it should be modeled based on discharge and concentration of trace elements.

By comparison of guideline values proposed by WHO (2011) and USEPA (2009) for drinking water (mentioned in the first column Table 1), it is suggested that most of the thermal waters in the region are enriched in trace elements with values much higher that the guidelines. The absolute values are tremendous in some cases, and in addition, the factor of exeedance that indicates the measure of exeedance of the trace element average concentration compared to the guideline values is very large for $\mathrm{As}, \mathrm{Cl}, \mathrm{Mn}$ and $\mathrm{Sb}$. In fact it appears that As is the most important environmental and health concern in the area.

\section{Conclusion}

The thermal springs in two areas studied in this research include Neer (situated in the southern part and far from the young vent of volcano and issued from the older volcanic flows) and Meshkinshahr (located in northwestern part near to the volcanic vent and on the youngest volcanic lava flows). The distance from the main vent resulted in major differences in two areas so that, the springs in the former area show very high values of $\mathrm{EC}$ and $\mathrm{Cl}, \mathrm{As}, \mathrm{B}, \mathrm{Pb}, \mathrm{Cu}, \mathrm{Sb}$ and $\mathrm{V}$. The latter springs are enriched in $\mathrm{Al}, \mathrm{Fe}, \mathrm{Mn}, \mathrm{Zn}$, and $\mathrm{Si}$. The $\mathrm{pH}$ values in the Neer springs are neutral to slightly alkaline while in the Meshkinshahr area, $\mathrm{pH}$ are mostly acidic to neutral.

The springs acquired their high content of their trace elements from the hydrothermal water released from magmatic system and also through interaction of the hydrothermal fluids with the surrounding volcanic rocks.

Finally, these springs with very high concentrations of potentially toxic elements such as arsenic are used for balneological purposes and also the runoff of the springs find their way to the streams in the area which are intended to be used for drinking water. Therefore, they would have adverse environmental and health impacts on the local communities and also on the hundreds of thousands of tourists using the springs annually.

\section{References}

Bargagli R., Cateni D., Nelli L., Olmastroni S., \& Zagarese B. (1997) Environmental impact of trace element emissions from geothermal power plants. Archives of Environmental Contamination and Toxicology, 33:172-181

Cruz J.V. \& Franca Z. (2006) Hydrogeochemistry of thermal and mineral water springs of the Azores archipelago (Portugal) Journal of Volcanology and Geothermal Research 151:382-398

Davraz A. (2008) Hydrogeochemical and hydrogeological investigations of thermal waters in the Usak Area (Turkey). Environmental Geology, 54:615-628

Elhatip H., Afsin M., Kuscu I., Dirik K., Kurmac Y., \& 
Kavurmaci M. (2004) Estimation of environmental impacts on the water quality of Incesu-Dokuzpinar Springs in Kayseri, Turkey. Bulletin of Engineering Geology and the Environment, 63:255-260

Federico C., Aiuppa A., Favara R., Gurrieri S., \& Valenza M. (2004) Geochemical monitoring of groundwaters (1998-2001) at Vesuvius volcano (Italy). Journal of Volcanology and Geothermal Research, 133:81-104

Gemici U., \& Filiz S. (2001) Hydrochemistry of the Cesme geothermal area in western Turkey. Journal of Volcanology and Geothermal research, 110:171-187

Gemici U., \& Tarcan G. (2004) Hydrogeological and Hydrogeochemical Features of the Heybeli Spa, Afyon, Turkey: Arsenic and the Other Contaminants in the Thermal Waters. Bulletin of Environmental Contamination and Toxicology, 72:1107-1114

Gemici U., Tarcan G., Colak M., \& Helvaci C. (2004) Hydrogeochemical and hydrogeological investigations of thermal waters in the Emet area (Kutahya, Turkey). Applied Geochemistry, 19:105 $-117$

Gultekin F., Hatipoglu E., \& Ersoy A..F (2011) Hydrogeochemistry, environmental isotopes and the origin of the Hamamayagi-Ladik thermal spring (Samsun, Turkey). Environment Earth Science, 62:1351-1360

Guo Q., \& Wang Y. (2009) Trace Element Hydrochemistry Indicating Water Contamination in and Around the Yangbajing Geothermal Field, Tibet, China. Bulletin of Environmental Contamination and Toxicology,83:608-613

Lima A., Cicchella D., \& Di Francia S. (2003) Natural contribution of harmful elements in thermal groundwaters of Ischia Island (Southern Italy). Environmental Geology, 43:930-940

Loppi S. (2001) Environmental distribution of mercury and other trace elements in the geothermal area of Bagnore (Mt. Amiata, Italy). Chemosphere,
45:991-995

Modabberi S., \& Moore F. (2004) Environmental geochemistry of Zarshuran Au-As deposit, NW Iran. Environmental Geology, 46(6-7):796-807

Nriagu J.O. (1989) A global assessment of natural sources of atmospheric trace metals. Nature, 338:47-49

Pehlivan R. (2003) The effects on human health and hydrogeochemical characterisitics of the Kirkgecit and Ozancik hot springs, Canakkale, Turkey. Environmental Geochemistry and Health, 25:05-217

Smedley P.L., \& Kinniburgh D.G. (2002) A review of the source, behaviour and distribution of arsenic in natural waters. Applied Geochemistry, 17:517-568

USEPA (2009) List of Contaminants \& their MCLs http://water.epa.gov/drink/contaminants/upload/mcl -2.pdf visited at 10 January 2012

Valentino G.M., \& Stanzione D. (2004) Geochemical monitoring of the thermal waters of the Phlegrean Fields. Journal of Volcanology and Geothermal Research, 133, 261-289

Vengosh A., Helvaci C., \& Karamanderesi I.H. (2002) Geochemical constraints for the origin of thermal waters from western Turkey. Applied Geochemistry, $17: 163-183$

Welch A.H., Westjohn D.B., Helsel D.R., \& Wanty R.B. (2000) Arsenic in ground water of the United States: occurrence and geochemistry. Ground Water, 38, 589-604

WHO (2011) Guidelines for drinking-water quality, fourth edition. World Health Organization. Geneva.

Yalcin T. (2007) Geochemical characterization of the Biga Peninsula thermal waters (NW Turkey). Aquatic Geochemistry, 13:75-93

Yoshizuka K., Nishihama S., \& Sato H. (2010) Analytical survey of arsenic in geothermal waters from sites in Kyushu, Japan, and a method for removing arsenic using magnetite. Environmental Geochemistry and Health, (2010) 32:297-302. 